\title{
Effect of Escherichia coli on Semen Quality of Infertile Human
}

\section{Male}

\author{
Vijay Kumar* and Neelam Garg \\ Department of Microbiology, Kurukshetra University, India
}

*Corresponding author: Vijay Kumar, Department of Microbiology, Kurukshetra University, Kurukshetra, Haryana, India, Email: vijaykuk@live.com

\section{Research Article}

Volume 3 Issue 3

Received Date: June 26, 2019

Published Date: July 05, 2019

DOI: $10.23880 / v i j-16000214$

\section{Abstract}

Male genital tract infections are one of the most major causes of infertility worldwide. It is expected that about $15 \%$ of male infertility is due to genital tract infections. These infections may contribute to deterioration of various sperm parameters, especially in infertile men. The negative effects of many bacteria on human spermatozoa have been widely reported. The aim of this study was to investigate the effect of Escherichia coli on the semen of infertile men and their effect on sperm quality. Sixty seven semen samples of infertile males were investigated by standard bacterial culture methods. WHO guidelines were followed to perform standard semen analysis. We found that E. coli was present in infertile males and there was a relation between $E$. coli infection and semen quality.

Keywords: E. coli; Infection; Infertility; Semen

Abbreviations: GTI: Genital Tract Infections; CPX: Ciprofloxacin; GEN: Gentamycin; CTX: Cefotaxime; STR: Streptomycin; TET: Tetracyclin; AMP: Ampicillin; IPM: Imipenem.

\section{Introduction}

Infertility is a complex human health situation which particularly alters the quality of life in couples facing the condition. Infertility results from multiple factors that are responsible for impairments of reproductive function in humans. Male urogenital tract infection is one of the most major causes of infertility worldwide. It is estimated that about $15 \%$ of male infertility is related to genital tract infections (GTI) [1]. GTI and consequent inflammation in male reproductive system may comprise sperm cell function and whole spermatogenic process. Escherichia coli is the most frequently isolated and studied genital organism in its regard to male infertility. In an investigation the mechanism of immobilization of spermatozoa by E. coli; they reported a soluble, dialyzable, heat stable, spermatoxic factor which immobilizes spermatozoa without agglutinating it [2]. $E$. coli is also the principle microorganism causing prostatitis and epididymitis [3,4].

The negative effect of $E$. coli on semen quality is due to its effect on motility and due to impaired acrosomal function. In 1996 a two-step mechanism was suggested for showing the negative impact of $E$. coli on the spermatozoa; firstly by the interaction by adhesion and later on the destruction of sperm membrane [5]. In another report reported the agglutination of spermatozoa due to adhesion to E. coli leading to morphological alterations in sperm involving plasma membrane and degeneration of acrosome [6].

Microorganisms might affect the male reproductive function causing the alterations in cell morphology, 


\section{Virology \& Immunology Journal}

reducing ability for the acrosome reaction and also causing the agglutination of motile sperm $[7,8]$. The aim of this study was to investigate the semen sample of infertile men and to analyse the influence of bacterial pathogens on the sperm quality.

\section{Materials and Methods}

\section{Study Population}

The study population consisted of sixty seven men with fertility disorders who contacted the Fertility Clinics of Kurukshetra. The average age of men was 35.07 years. The study was conducted in the Department of Microbiology, Kurukshetra University, Haryana state of India from January 2018 to December 2018. The samples were protected from extremes of temperature i.e. not less than $20^{\circ} \mathrm{C}$ and not more than $40^{\circ} \mathrm{C}$ during transport to the work area. Experiments were performed within $1 \mathrm{~h}$ of obtaining samples. The samples showing normal semen parameters according to WHO were used as control [9].

\section{Sample Collection}

Semen samples of 67 infertile men attending to infertility clinics were collected in the clinic. The patients have not taken any antibiotic from one week before collecting a semen sample. Before collecting the sample, patients must wash their hands and genital area with soap and water and the patients were instructed to ensure that all the ejaculate, especially the first sperm rich portion were included. Samples were collected in sterile plastic containers used for collecting of semen sample. Then, all of the samples were rapidly transferred to microbiology laboratory.

\section{Ethical Clearance}

The protocols for the present study were approved by the Institutional Ethics Committee of Kurukshetra University, Kurukshetra.

\section{Semen Parameter Analysis}

The semen samples were allowed to liquefy at $37 \mathrm{oC}$ for 30 minutes before examination. After that the samples were analysed for sperm parameters such as appearance, volume, $\mathrm{pH}$, viscosity, count, motility, morphology, presence of other cells like epithelial cell or round cell, and sperm agglutination were recorded according to the WHO guidelines.

All the procedures above were carried out in duplicate and the results were compared for maximum acceptable differences between replicate results in order to achieve low sampling error according to WHO specification [9].

\section{Microbiological Analysis}

Standard bacterial culture method (on blood agar, Mac conkey agar) was performed for each semen sample to detect microbial agents. Cultures were incubated at $37^{\circ} \mathrm{C}$ for 24-48 h. Each plate was examined for evidence of growth and the isolates identified by standard biochemical tests [10].

\section{Antimicrobial Sensitivity Testing}

The antimicrobial sensitivity testing was done on each of the isolates by the Kirby-Bauer disk diffusion method [10].

\section{Statistical Analysis}

The relationships between GTIs and semen parameters were analyzed using Chi-square $(\chi 2)$ test.

\section{Results}

\section{Semen Parameters}

During our study, 67 semen samples were received from the patients with fertility disorders who contacted the Fertility Clinics of Kurukshetra. The mean age of the study patients was 35.07 years. The $23(34.33 \%)$ number of patients were below the age group of 30 years and 44 (65.67\%) patients were belonging to the age group of more than 30 years.

Out of 67 samples analysed based on the guidelines of WHO, 29 (43.28\%) had normal sperm count, 33 (49.25\%) oligozoospermia and $5(7.46 \%)$ had azoospermia (Figure 1).

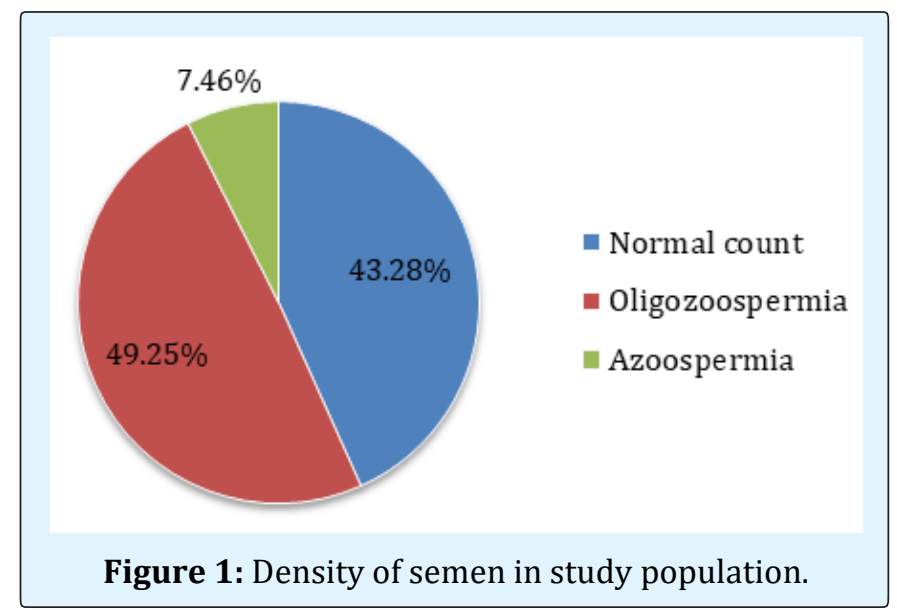




\section{Virology \& Immunology Journal}

Semen parameters of infertile males with genital tract infections were significantly different than in healthy individuals used as control. Volume of semen and number of sperm cells was lower in infected individuals. Also the motility and vitality was reduced as compared to healthy individuals, and this difference was found to be statistically significant $(\mathrm{p}<0.05$; Table 1$)$.

\begin{tabular}{|c|c|c|c|}
\hline Semen parameters & Healthy controls & $\begin{array}{c}\text { Infertile individuals without } \\
\text { GTI }\end{array}$ & $\begin{array}{c}\text { Infertile individuals with } \\
\text { GTI }\end{array}$ \\
\hline Volume (mL) & $2.8 \pm 0.5$ & $2.2 \pm 0.5$ & $1.9 \pm 0.7$ \\
\hline Concentration of sperm cells (1x106/mL) & $61 \pm 52$ & $20 \pm 9$ & $17 \pm 5$ \\
\hline Rapid and slow progression of sperm cells & $67 \pm 11$ & $29 \pm 10$ & $11 \pm 4$ \\
\hline (\%) & $29 \pm 9$ & $53 \pm 12$ & $89 \pm 16$ \\
\hline Immobilized sperm cells (\%) & $41 \pm 6$ & $15 \pm 7$ & $12 \pm 5$ \\
\hline Morphology (\%) & $75 \pm 10$ & $63 \pm 11$ & $61 \pm 10$ \\
\hline Vitality (\%) & & 2 & \\
\hline
\end{tabular}

Table 1: Analysis of semen ejaculated from healthy men and infertile patients with and without genital tract infection.

\section{Microbiological Analysis}

Among the 67 samples $42(62.68 \%)$ were found to be infected with various organisms. E. coli (64.28\%) was the most common microorganism isolated from the patients. About $80 \%$ of the azoospermic samples were found to be infected; $51.51 \%$ of the oligospermic samples were infected while $48.27 \%$ of those with normal concentration were infected.

\section{Antimicrobial Susceptibility Testing}

When the isolated E. coli were tested against the commonly used antimicrobial drugs, showed that 17 isolates were susceptible to ciprofloxacin, 12 to gentamycin, 18 to cefotaxime, 3 to streptomycin, 5 to tetracyclin, 22 to ampicillin and 25 to imipenem. Some of them are resistance to various antibiotics (Table 2).

\begin{tabular}{|c|c|}
\hline Organism & Escherichia coli $(\mathbf{n = 2 7})$ \\
\hline CPX & $17(62.9)$ \\
\hline GEN & $12(44.4)$ \\
\hline CTX & $18(66.7)$ \\
\hline STR & $3(11.1)$ \\
\hline TET & $5(18.5)$ \\
\hline AMP & $22(81.5)$ \\
\hline IMP & $25(92.6)$ \\
\hline
\end{tabular}

Table 2: Antibiotic susceptibility profile of $E$. coli.

CPX-ciprofloxacin; GEN-gentamycin; CTX-cefotaxime; STR-streptomycin; TET-tetracyclin; AMP-ampicillin; IPMimipenem.

\section{Discussion}

Infertility in the male partner contributes to approximately half of all cases. Infertility can be defined as a failure to conceive in a couple trying to reproduce for a period of 2 years of constant unprotected sex. Bacterial GTIs may contribute to deterioration of various sperm parameters, especially in infertile men. It is well known that these parameters are important in the fertility potential of a male. Several studies have examined the role GTIs on the parameters of sperm for the fertility potential but it is still controversial [11,12]. In our study we have shown that the bacterial genital tract infections may have the negative effect on the infertile males and based on the density of sperms in the samples nearly half of the population was oligospermic $(49.25 \%)$. The changes in the morphology and motility are more commonly observed in the oligospermic individuals. Similar findings have been reported in the Jajoo and Kalyani [13] and Owolabi, et al. [14].

The presence of bacteria in the studied population is $62.68 \%$. The similar results were obtained in the Isaiah, et al. [15] and Merino et al. [16]. Lower rates of were also reported in Golshani, et al. [17] and Cottell, et al. [18]. Escherichia coli (64.28\%) has dominated in this study as compared to other studies where Staphylococcus aureus and S. epidermidis has been isolated $[14,19]$. In some cases E. faecalis has been the main isolate $[20,21]$.

The negative effect of $E$. coli on sperm motility and number has been reported by Diemer, et al. [22] and Prabha, et al. [23]. Similar negative effects of other bacteria like E. faecalis, U. urealyticum, and M. morganii shown by Moretti, et al. [24].

\section{Conclusion}

In conclusion, the role of bacterial genital tract infections should be taken into consideration as they may 


\section{Virology \& Immunology Journal}

have additional negative effect on the sperm quality and motility in infertile males. Microbiological analysis must be carried out in the diagnosis of male infertility and suitable antibiotic should be given to control the infection.

\section{Conflict of Interest}

The authors declare that they have no conflict of interests.

\section{References}

1. Mascarenhas MN, Flaxman SR, Boerma T, Vanderpoel S, Stevans GA (2012) National, regional and global trends in infertility prevalence since 1990: a systematic analysis of 277 health surveys. PloS Medicine 9(12): e1001356.

2. Paulson JD, Polakoski KL (1997) Isolation of a spermatozoal immobilization factor from E. coli filtrates. Fertility and Sterility 28: 182-185.

3. Comhaire FH, Vermeulen L, Schoonjans F (1987) Reassessment of the accuracy of traditional sperm characteristics and adenosine triphosphate (ATP) in estimating the fertilizing potential of human semen in vivo. International Journal of Andrology 10(5): 653662.

4. Purvis K, Christiansen E (1993) Infection in the male reproductive tract. Impact, diagnosis and treatment in relation to male infertility. International Journal of Andrology 16(1): 1-13.

5. Diemer T, Weidner W, Michelmann HW, Schiefer HG, Rovan E, et al. (1996) Influence of Escherichia coli on motility parameters of human spermatozoa in vitro. International Journal of Andrology 19(5): 271-277.

6. Huwe P, Diemer T, Ludwig M, Liu J, Schiefer HG, et al. (1998) Influence of different uropathogenic microorganisms on human sperm motility parameters in an in vitro experiment. Andrologia 30: 55-59.

7. Kohn FM, Erdmann I, Oeda T, el Mulla KF, Schiefer HG, et al. (1998) Influence of urogenital infections on sperm functions. Andrologia 30(1): 73-80.

8. Monga M, Roberts JA (1994) Spermagglutination by bacteria: receptor-specific interactions. Journal of Andrology 15(2): 151-156.

9. World Health Organization (2010) WHO Laboratory Manual for the Examination and processing of Human
Semen. World Health Organization, Geneva, Switzerland.

10. M Cheesbrough (2000) District Laboratory Practice in Tropical Countries Part 2. Cambridge University Press, UK.

11. Sanocka D, Kurpisz M (2004) Reactive oxygen species and sperm cells. Reproductive Biology and Endocrinology 2: 12.

12. Menkveld R, Kruger TF (1998) Sperm morphology and male urogenital infections. Andrologia 30(1): 4953.

13. Jajoo S, Kalyani K (2013) Prevalence of abnormal semen analysis in patients of infertility at a rural setup in Central India. International Journal of Reproduction, Contraception, Obstetrics and Gynecology 2(2): 161-164.

14. Owolabi AT, Fasubaa OB, Ogunniyi SO (2013) Semen quality of male partners of infertile couples in Ile-Ife, Nigeria. Nigerian Journal of Clinical Practice 16(1): 37-40.

15. Isaiah IN, Nche BT, Nwagu IG, Nnanna II (2011) Current studies on bacterospermia the leading cause of male infertility: a proteg'e and potential threat towards mans extinction. North American Journal of Medical Sciences 3(12): 562-564.

16. Merino G, Carranza-Lira S, Murrieta S, Rodriguez L, Cuevas E, et al. (1995) Bacterial infection and semen characteristics in infertile men. Archives of Andrology 35(1): 43-47.

17. Golshani M, Taheri S, Eslami G, Suleimani Rahbar AA, Fallah F, et al. (2006) Genital tract infection in asymptomatic infertile men and its effect on semen quality. Iranian Journal of Public Health 35(3): 81-84.

18. Cottell E, Harrison RF, McCaffrey M, Walsh T, Mallon E, et al. (2000) Are seminal fluid microorganisms of significance or merely contaminants? Fertility and Sterility 74(3): 465-470.

19. Alekwe L, Osamudiamen AI, Aberare LO (2013) Association between bacteriospermia and abnormal semen characteristics. Pakistan Journal of Medical and Health Sciences 7(1): 3-6.

20. Domes T, Lo KC, Grober ED, Mullen JB, Mazzulli T, et al. (2012). The incidence and effect of 


\section{Virology \& Immunology Journal}

bacteriospermia and elevated seminal leukocytes on semen parameters. Fertility and Sterility 97(5): 10501055.

21. Balmelli T, Stamm J, Dolina-Giudici M, Peduzzi R, Piffaretti-Yanez A, et al. (1994) Bacteroides ureolyticus in men consulting for infertility. Andrologia 26(1): 35-38.

22. Diemer T, Huwe P, Michelmann HW, Mayer F, Schiefer HG, et al. (2000) Escherichia coli-induced alterations of human spermatozoa. An electron microscopy analysis. International Journal of Andrology 23(3): 178-186.

23. Prabha V, Sandhu R, Kaur S, Kaur K, Sarwal A, et al. (2010) Mechanism of sperm immobilization by Escherichia coli. Advances in Urology.

24. Moretti E, Capitani S, Figura N, Pammolli A, Frederico MG, et al. (2009) The presence of bacteria species in semen and sperm quality. Journal of Assisted Reproduction and Genetics 26(1): 47-56. 